\title{
国内外监狱图书馆建设研究
}

\section{Research on the Construction of Prison Library at Home and Abroad}

\section{吴忠跃}

Zhongyue $\mathrm{Wu}$

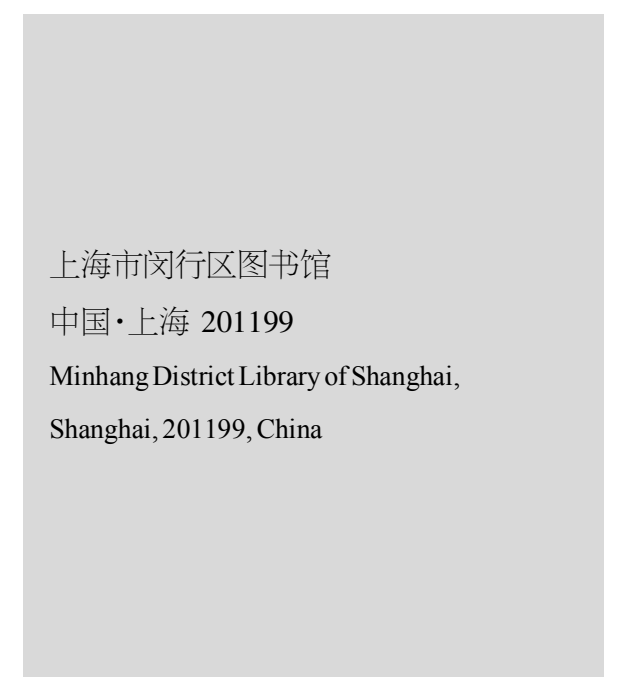

\section{1 引言}

图书馆是国家文化发展水平的重要标志, 是滋养民族心 灵、培育文化自信的重要场所。而监狱图书馆是监狱内重要的 文化设施, 是犯人享受阅读自由的基本人权的保障, 是监狱改 造有益的辅助教育手段，也是公共文化服务日益普及的重要 指标。笔者在基层图书馆一线工作已二十多年,曾在上海青浦 监狱、上海新收犯监狱、上海青少年管教所有多年的志愿帮教 经历, 接触过各种类型的帮教对象, 通过和他们的深人交流, 了解到不少帮教对象身处 “高墙” 内, 对自己曾经的错误行为 深有悔意, 渴望能及早地回归社会。而在和他们的交流中, 笔 者发现他们普遍担忧的内容包括以下三点: 一是由于漫长的 刑期造成与社会的脱节, 出去后会感到迷茫;二是在监狱缺乏 有效的手段来弥补自身知识的匮乏; 三是枯燥的监狱改造需 要知识文化服务等辅助手段来润滑。而图书馆服务恰好能部 分解决他们的这些问题，监狱图书馆这一特定场所不应当被 遗忘和忽视。

为监狱犯人提供图书馆服务, 既符合国际人道主义精神 和《中华人民共和国监狱法》精神, 也符合中国《图书馆服务宣 言》中的“信息公平、服务平等、利益全民、教育教化”的精神 [1]。笔者也希望通过自身的实践,结合国内外监狱图书馆的成 熟经验来谈谈监狱图书馆服务。

\section{2 监狱图书馆发展的现状}

\section{1 国外监狱图书馆的发展与经验}

从世界范围来看, 监狱图书馆得到研究和重视, 也是一个 渐进的过程。1955 年, 联合国大会通过的《囚犯待遇最低标 准》第 40 条规定: “每个机构都应该有一个让不同受刑人使用 的图书馆, 馆藏要包含适当的娱乐和指引性书籍, 并且受刑人 要被鼓励善用之。”国际图联下属的弱势人群服务图书馆专业 组很早就开始制订了关于监狱图书馆的服务政策, 1990 年欧 洲理事会的《监狱教育报告》专门论述了监狱图书馆的建立。 1992 年出版的《监狱犯人图书馆服务指南》从根本上制定了 监狱图书馆的基本原则, 1995 年进行了第 1 次修订, 2005 年 还出版了修订后的第三版, 为国际图书馆界开展此项服务提 供了基本的指导和规范。

在监狱图书馆理论实践的探索发展中, 美国参与并主导 了相关国际规则的制定,结合美国政府的相关规则, 美国图书 馆协会 (ALA) 制定了一系列国内的标准和规定。1981 年颁布 了《成人惩教机构图书馆标准》(Library Standards for Adult Correctional Institutions), 1999 年出版了《青少年惩教机构图书馆 标准》(Library Standards for Juvenile Correctional Facilities)。而 地方性的细则则更加广泛, 针对性、操作性更强[1]。美国在1978 年建造大型监狱时, 就考虑把图书馆设计在监狱的规划之内, 中小型监狱则由当地的公共图书馆联合起来服务于监狱。 
在欧洲, 意大利在 1975 年 7 月 26 日通过新的《监狱法》, 强调囚犯基本人权的保障, “监狱待遇应符合人道, 应保障尊 重人格” (第 1 条第 1 款), 第 12 条第 2 款规定: “监狱还应当 设立拥有图书和期刊的图书馆, 并且由根据第 16 条第 2 款成 立的委员会选择图书和期刊。囚犯和被收容人的代表参加开 办图书馆的服务工作 ${ }^{[3]}$ 。”意大利监狱图书馆的运行管理来 看, 主要由市立图书馆与监狱合作, 提供图书管理人员和书籍 ${ }^{[4]}$ 。澳大利亚要求各类监狱严格执行国际图联所制定的《监狱 犯人图书馆服务指南》的相关政策, 明确监狱图书馆的监管主 体、使命、目标、资金来源和管理责任, 如澳大利亚 JUNEE 矫 正中心图书馆主管机构有明确的年度预算, 有 3 5 年的长期 规划, 硬件建设、馆藏建设、人员配置均按照《监狱犯人图书馆 服务指南》的要求来实施 ${ }^{[5]}$ 。

\section{2 中国监狱图书馆的发展状况}

中国对监狱图书馆的研究开展得比较晚, 首先在监狱图书 馆的理论研究方面发展迟缓; 其次, 专家学者不重视; 再次, 研 究力度小、方向不全面; 最后, 有价值的研究成果少。笔者以“监 狱图书馆”为检索词, 通过主题检索人口, 对知网的中文文献进 行检索, 得到的结果为文献数量为 58 , 从统计结果看 2018 年 文献数量为 0,2019 年文献数量仅有 1 篇。中国监狱图书馆研 究的停滞, 也反映了监狱图书馆发展的困难状况 ${ }^{[6]}$ 。

相关的法律法规在 20 世纪 90 年代后陆续出现。在中国, 随着公共图书馆服务的延伸, 公共图书馆对弱势群体的关注 和服务也将成为其工作内容的重要组成部分, 而监狱的常规 教育包含思想文化技术教育、监区文化建设、社会帮教、心理 矫治等内容, 两者可以有效结合。自 1984 年浙江省图书馆与 该省第六监狱建立图书流通的开始, 全国各地图书馆纷纷与 监狱建立联系, 为监狱提供服务。由此, 针对实践的研究逐步 开始。陈俊民对江西省图书馆在该省劳动教养工作管理局建 立图书流通站从酰酿、尝试和建站后获得的社会效益进行了 细致的论述 ${ }^{[7]}$; 刘一丁对浙江图书馆在监狱建立图书流通站 的工作内容和推动监狱教育改造服刑人员的成绩进行了概 述; 尹美华、叶洤林、王俊懿分别介绍了上海地区、德兴市、朝 阳县的公共图书馆对监狱服刑人员提供服务的方式和内容; 杨明英对常德市图书馆监狱分馆的特点进行了论述, 并提出 了对监狱图书馆建设的启示 ${ }^{[8]}$ 。监狱教育与图书馆的结合, 顺 应了时代的要求。

\section{3 监狱图书馆发展存在的问题}

\section{1 政策立法}

中国监狱图书馆发展缓慢的首要原因还是政策、立法方
面的滞后。没有政策法规的依据, 监狱图书馆的资金、人员得 不到切实的保障。现有的监狱图书馆普遍规模小, 设施功能不 全, 馆藏陈旧, 结构不合理, 不少还只流于形式。目前部分监狱 图书馆缺乏统一的协调与管理, 还在走同样的路, 面临同样的 困境。

现有法律中, 1994 年全国人大通过的《监狱法》第 66 条 规定: “罪犯的文化和职业技术教育, 应当列入所在地区教育 规划。监狱应当设立教室、图书阅览室等必要的教育设施。” 1995 年司法部关于创建现代化文明监狱的标准和实施意见 中规定: “健全教育改造机构, 落实教育改造管理制度, 保证教 育改造经费。有固定的教学场所、必要的教育改造设备、电化 教育设施和图书、阅览、活动室及运动场等文化、体育活动设 施。”2018 年颁布的《中华人民共和国公共图书馆法》虽有以 弱势群体为服务对象，但未明确弱势群体包括监狱服刑人员。 所以制定一部包含责任主体、服务规范、运行机制的监狱图书 馆法规是当务之急。

\section{2 重视程度}

监狱是特殊的学校, 是改造犯人的地方, 监狱图书馆的发 展状况很大程度上取决于监狱管理方的认识程度和重视程 度。但实际上, 监狱管理方比较注重对服刑人员思想和文化的 教育, 却忽视了图书等文化服务对犯人在改造过程中潜移默 化、非显性的作用。由于日常繁重的管教工作和出于安全的考 虑, 管教人员往往既无心也无力开展图书相关的服务。

\section{3 社会力量的支持}

监狱在押人员不同于普通的社会弱势群体, 由于其封闭 的环境和安全性等因素的考虑, 服务方式不能以传统的方式 进行。监狱也分为看守所、新收犯监狱、青少年管教所等类型, 都有各自的特点, 社会力量即使想助力监狱图书馆往往也会 面临许多的障碍, 并且监狱方、管理方在寻求社会力量的支持 时会有不同的考量。

\section{4 在押人员对图书馆的态度}

监狱图书馆由于提供的图书种类有限, 更新不及时, 服务 不完善, 限制条件较多, 在押人员使用图书馆的积极性不高或 持无所谓的态度。另外, 在押人员所处的环境比较特殊, 他们 往往对相关活动的态度都比较谨慎。

\section{4 监狱图书馆建设}

\section{1 制度的建设}

结合国内外监狱图书馆发展的经验, 从政策层面上讲, 首 先要建立健全能够指导监狱图书馆建设的法律规范和政策依 据; 从微观上讲, 每一个监狱图书馆必须建立正规的图书分类 
制度和各项管理制度。可以成立图书馆专家小组之类的机构, 人员由图书馆专业人员、监狱管理方、在押人员组成, 共同参 与对图书馆基本框架的设立和重要事项的决策，基本的制度 包括图书馆人馆须知、图书借阅制度、图书馆工作人员制度等。

在制度建设时, 需要重点注意以下三个原则: 第一, 安全审 慎原则。监狱图书馆不同于普通的图书馆, 读者是在押人员, 有 其特殊性,藏书的采集也有诸多的限制。第二,平等、自由的服 务原则。监狱图书馆应当能让所有在押人员平等便利地利用 图书馆服务。监狱有其特殊性, 在安全的前提下, 图书馆的开 放时间要尽量避免与在押人员的文化教育时间、劳动改造时 间等冲突;满足监狱内活动不受限制的在押人员, 不同年龄、 不同文化程度、不同文化背景以及残疾在押人员等的不同需 求,让在押人员在规定的时间可以自由地去图书馆借阅图书, 享受真正的阅读自由。第三, 自主、独立的原则。在经费方面, 主管部门应该确保监狱图书馆作为一个独立的单位给予资 金, 在经费预算上应涵盖人员工资、馆藏建设、设备设施、学术 交流、员工培训以及数据库购买等方面。监狱图书馆虽是监狱 的一个组成部分, 但由于其专业性应当保持运行的独立性。

\section{2 空间的选定}

空间的选定包括选址、空间设计、设施、设备等,对于新建 的监狱图书馆, 在设施设备的选择上, 监狱可考虑图书馆的特 点, 放置舒适的阅览座椅, 打造光线明亮的阅读环境, 逐步建 立起图书馆知识中心、学习中心的形象, 使其成为在押人员精 神休憩的港湾。还应考虑监狱的具体情况以及方便在押人员 使用的原则来设计, 营造一个安静、舒适、安全的阅读环境。图 书馆选址应选择在监狱建筑的中心地带, 这样方便在押人员 前往,也可以临近或在教育部门内部等, 便于管理。

\section{3 馆藏建设}

馆藏资料的选择在不威胁到监狱安全的情况下应不受审 查制度的限制; 应充分考虑在押人员的教育水平、年龄、语言、 种族等背景; 应配合监狱内的教育活动, 调动在押人员的兴趣 和需求。笔者也做过相关的读者调查问卷, 发现受欢迎的图书 主要有三类:第一,武侠小说、侦探小说,这与在押人员的文化 程度有很大的关系; 第二, 技能类书籍, 阅读这类书籍的在押 人员希望能学一技之长, 出去后可以自食其力, 能快速地融入 社会; 第三,自学类考试书籍, 阅读这类书籍的在押人员还是 希望能利用这段“空档期”让自己得到提升, 有助于出狱后找 工作、融入社区等。

在馆藏建设时, 还可以考虑以下三点: 第一, 尽可能地配 置法律汇编、案例汇编和法律图书, 因为服刑人员迫切需要学 习法律知识来提高自己的法律意识; 第二, 为文化程度较低者
配置九年制教育读本, 使其具备基本的阅读能力, 把刑期变成 “学期”; 第三, 提供正能量和主旋律的读本, 在押人员中有较 多心理异常和性格缺陷的人员, 需要用正确的世界观、人生 观、价值观去引导他们, 使他们自觉准守行为规范, 真心实意 地接受改造, 出去后能尽快适应社会。

\section{4 内部管理}

监狱图书馆目前大多以管教干部和在押人员来管理,但 由于他们缺乏专业知识和管理经验, 只是充当图书保管员的 角色。监狱图书馆可以通过公共图书馆的参与, 对管理图书馆 的管教干部和在押人员进行相关技能的培训, 使其具备基本 的图书馆业务知识, 能做到日常的正常运行。德国北莱茵-威 斯特伐利亚洲明斯特监狱图书馆的服务创新值得借鉴, 它采 用三层管理模式, 实行专业化管理, 由专业图书馆管理员管理 监狱图书馆: 第一层, 由监狱图书馆辅助员负责图书馆的日常 事务; 第二层, 由图书馆督管员监管图书馆的日常运作, 他们 与监狱管理人员一起协调管理监狱图书馆, 负责挑选、培训和 监管图书馆辅助员; 第三层, 由职业图书馆馆员协调整个图书 馆的管理,使监狱图书馆发展走向专业化、持续化 ${ }^{[9]}$ 。

\section{5 监狱图书馆与区域图书馆的合作}

\section{1 监狱图书馆与区域图书馆合作的形式}

考虑到行政区域属地管理和便捷性, 监狱图书馆的发展 离不开和区域图书馆的合作, 采取的形式主要包括以下四种: 第一, 监狱图书馆由于空间和经费所限, 可以通过接受捐赠等 形式增加馆藏。第二, 采取集体借阅的形式。监狱图书馆毕竟 空间有限, 藏书也很难满足全体在押人员的借阅需求, 按人均 10 册的要求, 大部分监狱图书馆短期内显然是无法达到的, 集体借阅能很好地解决这一矛盾。第三, 可以开展讲座等形式 的知识服务。在监狱这样特定的环境中, 在押人员还是存在许 多共同的知识需求, 区域图书馆可以尝试通过菜单式点播等 形式对在押人员进行讲座服务。笔者所在图书馆曾对上海市 未成年管教所开展过此类服务, 受到了在押人员的欢迎。第 四, 可以组织开展读书小组等形式的活动, 以书会友, 通过对 图书的讨论, 提升在押人员对书籍的理解, 增加阅读的兴趣。 但需要注意的是, 这些活动应与监狱的使命相配合, 在管理方 的批准和把控下进行。

\section{2 宣传和交流}

早年笔者曾与新收犯监狱进行过帮教活动, 对象是一批 20 岁左右的青年犯人, 这一年龄段的普遍特点是学历较低, 原生的家庭环境缺少关爱, 容易产生自暴自弃的想法。图书馆 专业人员的介人以图书为介质, 通过写信、面对面交谈等形 
式, 了解了帮教对象的想法, 适时提供合理的建议, 往往在犯 人的改造过程中能起到重要作用。帮教活动等形式一方面能 使犯人与社会不定时有间接的接触, 让他们意识到自己并没 有被社会所遗忘, 提振改过自新的信心, 同时也通过帮教者在 社会的影响, 增加人们对监狱的社会关注度。

\section{3 定期进行读者满意度的调查}

不同时期、不同监狱的在押人员读者需求还是有很大差 异的。要定期对在押人员进行满意度调查, 既要满足在押人员 的阅读需求, 也要引导在押人员正确的阅读兴趣; 成立由监狱 内管教干部、在押人员等组成的读书指导委员会; 多多参与同 行交流, 引进社会资源, 改变监狱图书馆封闭孤立的状况, 积 累办馆经验, 完善监狱图书馆理论和实践模式, 提高监狱图书 馆的影响力。

\section{4 改变人们的观念}

部分人认为在押人员在监狱中应受到惩罚, 在被限制人 身自由的同时还要被剥夺利用图书馆的权利, 不能得到有效 的知识信息也是理所当然的。但在押人员被关押本身就已经 受到了惩罚, 更何况刑期是有时限的, 在押人员总要回归社 会。监狱的作用不只是惩戒, 更重要的是改造和教育, 而图书 馆服务是教育的手段之一。

\section{5 监狱阅读推广的四个着力点}

5.5 .1 做“深”

监狱文化服务的难点是封闭、交流的不对称, 区域图书馆 可以利用监狱现有的信息化平台进行资源推送, 也可以把新 书推荐等内容制作成小手册进行发放, 还可以把比较受欢迎 的展览引入监区, 如把纪念改革开放四十周年的展览引入监 区, 通过图片和实物等档案资料, 生动地反映家乡改革开放的 历程与成果, 让在押人员切身体会到社会的变革和发展, 增强 自身改造回归社会的动力。

\section{5 .2 做“长”}

没有一个人是天生的罪犯, 之所以犯罪是有一个内外因 综合作用的渐变过程, 而教育改造同样需要这个过程。而鉴于 图书馆潜移默化、润物细无声的作用, 不能指望立竿见影、一 䟣而就, 要有长期作战的准备。

\subsection{3 做“精”}

监狱的在押人员有自身的特点, 不能把所有资源一股脑地 摆在他们面前, 不现实也没有效果。可以做“私人订制”, 如请专 家定制讲座, 讲一个 “中国传统文化与服刑改造”, 也可以将读 书会讨论的热门书籍活动视频制作成光盘由他们自主选择。

\section{5 .4 共享}

监狱图书馆需加强与外界的联系, 聘请图书馆馆员、法官、 律师、医生、作家等作为图书馆支援成员, 一方面可以利用他们 的特长, 发挥图书馆的作用, 另一方面也能提高各个层面的社 会关注度。同时, 监狱图书馆不仅可以和各类高校、公共图书馆 实现共享, 也可以在监狱图书馆之间共享,进行横向交流。

\section{6 结语}

现阶段, 公共图书馆为在押人员提供的服务得不到有效 规范, 也没有形成完整的体系, 基本停留在文献借阅的浅层次 上。图书馆和监狱分属不同的系统, 为保证监狱图书馆服务的 展开, 应该由政府牵头, 特别是地方政府, 组织监狱管理方和 图书馆行业专家在现有的图书馆法规和监狱法规的基础上制 定细化的、可操作性强的政策, 法规中须明确监狱图书馆的责 任主体和担负的管理责任、所需达到的远近期目标任务、资金 的来源。监狱图书馆必须由专业图书馆馆员监督和管理, 主要 工作人员必须具备相应的专业和技术资格, 必须具备监狱这 一复杂环境所需的知识及与特定人群人际交流的技能。各个 地区、各种类型的监狱图书馆可以依据此项政策, 根据当地情 况和自身特点制定中长期规划。只有建立监狱图书馆自身的 体系, 才能让在押人员真正地享受到文化服务的权益, 才能真 正做到公共图书馆服务的全覆盖。

\section{参考文献}

$[1]$ 郭海明. 解读《图书馆服务宣言》中的公共服务理念 $[\mathrm{J}]$. 图书馆 理论与实践, $2010(2): 27$.

[2]刘甲库.美国、挪威、日本监狱图书馆比较研究与借鉴 $[J]$. 图书 情报工作,2013(19):81-86.

[3]黄风译.意大利刑法典附意大利监狱法 $[\mathrm{M}]$. 北京: 中国政法大 学出版社,1998.

[4]刘伟.意大利监狱图书馆发展述评[J].辽宁公安司法管理干部 学院学报,2015(4):136-139.

[5]方树红.澳大利亚私营监狱图书馆的建设及启示 [J]. 图书情报, 2013(4):191-192.

[6]陈春艳,余筕雨.我国监狱图书馆研究状况述评(1986-2009) [J].公共图书馆,2009(4):92.

[7]陈俊民.在监狱建立图书流通站的尝试[J].江西图书馆学刊, 1990(2):25-26.

[8]杨明英.常德市图书馆监狱分馆建设时间[J]. 图书馆,2010(4): 132-133.

[9]孙会清.德国明斯特监狱图书馆服务 [J]. 图书馆论坛,2016(5): 129-134. 